\title{
ESTUDO DO MERCADO DE TRABALHO EM ARRANJO PRODUTIVO LOCAL (APL): TERRITÓRIO E PRODUÇÃO CERÂMICA EM SANTA GERTRUDES/SP
}

\section{A research of local labor markets in local productive arrange- ments (APL): Territory and ceramic production in Santa Gertrudes/SP}

\author{
Lucas Labigalini FUINI ${ }^{1}$
}

\begin{abstract}
RESUMO
O presente artigo trata da perspectiva de que toda aglomeração produtiva está associada a um respectivo mercado de trabalho local. No contexto de profundas modificações na atividade industrial e no mundo do trabalho que conduzem a novos formatos espaciais das relações econômicas. É discutido no texto a pertinência da noção de mercado de trabalho local a luz da atual ênfase dada aos aglomerados territoriais de pequenas e médias empresas - chamados de APLs (Arranjos Produtivos Locais)- a partir de seu potencial gerador de competitividade e desenvolvimento territorial. A partir desses pressupostos serão analisadas as principais características do mercado de trabalho inerente à territorialidade da indústria de revestimentos cerâmicos da região de Santa Gertrudes/SP.
\end{abstract}

Palavras-chave: mercado de trabalho local; território e arranjo produtivo local.

\begin{abstract}
Under the perspective that all productive clusters are related to a respective local labor market, the author analyzes, in this paper, the principal characteristics of labor market associated with Santa Gertrudes/ Sao Paulo region territoriality of manufacturing pavement ceramic. In the context of deep changes in manufacture activity and labor world that drives for new special forms of economic relations, the importance of local labor market notion behind of actual Little and Medium territorialized industries clusters valorization - named APL (Local Productive Arrangements) - are examined in this text, considering it promotes potential of competitiveness and territorial development.
\end{abstract}

Keywords: local labor market; territory and local productive arrangements. 
FUINI, L. L. Estudo do mercado de trabalho em arranjo produtivo local (APL) ...

\section{INTRODUÇÃO}

Como resposta à crescente globalização dos mercados e conseqüente flexibilização e desregulamentação das relações produtivas e trabalhistas, advém movimentos de recomposição das escalas territoriais pelas dinâmicas espaciais da indústria que levam à construção de novos formatos produtivo-territoriais com base na competitividade e desenvolvimento localizados. Dentre os formatos aventados destacam-se os Arranjos Produtivos Locais (APL), objeto de intenso debate teórico e político recente no Brasil e no mundo, pois que, articulam uma aglomeração de empresas setorialmente especializadas e geograficamente próximas com os atores e instituições locais, elevando a competitividade de pequenos negócios com resultados para o desenvolvimento econômico dos municípios.

Esses aglomerados industriais se constituem como sistemas concentrados que abarcam uma série de elementos justapostos, dentre os quais os mercados de trabalho locais se colocam como condição essencial da reprodução e ascensão de aglomerações produtivas e cuja análise cuidadosa se faz premente para o escopo das políticas de desenvolvimento regional atuais. Nesse sentido, efetuar-se-a um estudo do mercado de trabalho local de Santa Gertrudes/SP e de municípios próximos (Cordeirópolis e Rio Claro), região líder na produção de pisos e azulejos cerâmicos no Brasil, a partir da idéia de que esta área abarca um APL dotado de mercado de trabalho específico.

Posto isso, pactuamos com a proposta de George (1979) para um estudo geográfico do trabalho, por meio da análise:

1) Distinção de sistemas técnicos, econômicos e sociais que comportam formas particulares de articulação das diferentes atividades, da divisão da força de trabalho conforme formas e lugares de trabalho; 2) a avaliação das taxas de utilização da força de trabalho e de suas estruturas e técnicas; 3) o local de trabalho no tempo e no espaço vivido, a gênese de um direito do trabalho e dos quadros institucionais no plano nacional e internacional. A combinação de tais elementos deve dar meios a que se estabeleça uma classificação de sistemas de trabalho inerentes a estruturas econômicas e sociais, tendo cada uma domínio espacial próprio em determinada época da evolução histórica de cada grupo e cada espaço. [...]. (GEORGE, 1979, p. 13).

Este artigo procura, em suma, colocar em debate a justaposição das noções de "mercado de trabalho local" e "arranjo produtivo local" como base do desenvolvimento territorial de uma dada região, a luz da análise especifica da produção cerâmica no município paulista de Santa Gertrudes. Na primeira seção (1), efetua-se uma análise da concepção de mercado de trabalho local, considerando o trabalho tanto como fator de localização produtivo quanto um objeto de construção sócio-institucional. Na Segunda seção (2), coloca-se em questão a noção de APL, tão valorizada na atualidade, sob a hipótese de seu sucesso ser indissociável do mercado de trabalho que lhe dá sustentação. A terceira seção é dedicada ao estudo do mercado de trabalho do APL de Santa Gertrudes, suas características históricas e setoriais mais gerais, e a partir dos dados estatísticos (RAIS), alguns aspectos do emprego local.

\section{O MERCADO DE TRABALHO LOCAL: O ÂMBITO ESPACIAL DAS RELAÇÕES DE EMPREGO}

Uma consideração básica para se entender a lógica de espacialização do trabalho e das relações de emprego é partir da (re) interpretação da noção de divisão territorial do trabalho, admitindo que o trabalho como fator de produção ampliado tem uma mobilidade limitada entre os lugares, sendo definido pelas especializações produtivas regionais que alimentam demandas tecnológicas, relações com o local de trabalho e conflitos de emprego específicos (STORPER; WALKER, 1989, p. $155-182)^{2}$.

A relação do "trabalho" com seu contexto espacial se encontra profundamente modificada na atualidade graças aos profundos processos de reestruturação produtiva, com uso de novas tecnologias e formas de gestão da mão de obra, e pelas políticas locais de emprego, que acabaram atuando no sentido de dar maior liberdade alocativa ao capital industrial na busca de maior rentabilidade em lugares afastados das pressões sindicais e das altas remunerações, característico do emprego fordista ${ }^{3}$, disseminando-se formas de emprego

2 Storper e Walker (1989) utilizam Marx (1867) para ratificarem a idéia de que a força de trabalho exibe um alto nível de diferenciação geográfica contrariando uma visão da natureza única do trabalho. O trabalho difere fundamentalmente de comodities reais porque está incorporado na vida e no sentido da consciência humana e porque como atividade humana (trabalho), é um aspecto irredutível e único da existência humana e vida social.

3 Leborgne e Lipietz (1988) caracteriza o emprego fordista a partir da garantia aos assalariados de uma demanda efetiva que viabilizava o regime de acumulação intensiva. Deste modo, a partir de mecanismos como as convenções coletivas e o salário mínimo, garantia-se uma evolução de rendimentos dos empregados que acompanhava o aumento da produtividade e dos preços. 
mais flexíveis e precárias. Matoso (1995, p. 121-154) reconhece nesse movimento uma desestruturação do trabalho no Brasil, passando as empresas a fazerem uso de mecanismos de corte de pessoal ${ }^{4}$ e uso de empregos precários (tempo determinado, terceirizados), ação ratificada por políticas de corte neoliberal implantadas pelo Estado brasileiro favorecendo a flexibilidade na contratação e demissão de mão de obra e desconcentração espacial da produção via guerra fiscal entre Estados e municípios.

No entanto, o uso da noção de "mercado de trabalho local" ainda continua essencial, pois está na base da reprodução territorial e dissolução de "sistemas industriais concentrados locacionalmente". Considerase mercado de trabalho local como a concentração de trabalhadores em dado lugar, gerando economias de aglomeração e promovendo determinadas instituições e convenções que consolidam as qualificações e habilidades dos trabalhadores e regem com certa estabilidade o comportamento dos atores. Mas o mercado de trabalho vai além de uma simples bacia de empregos definida no plano da oferta e procura por emprego com certas qualificações nas zonas urbanas (SCOTT; STORPER, 1988, p. 35).

O mercado de trabalho local é caracterizado também pela dimensão social da força de trabalho local no âmbito de um conjunto de atitudes e práticas dos trabalhadores em torno de contrato de emprego e dos salários, das relações profissionais no seio das unidades de produção e da presença de um coletivo geográfico de trabalhadores atuando politicamente em torno dos sindicatos e associações representativas. Para Pires (2000, p.182), as relações salariais locais (aquelas relativas ao contrato de emprego) se expressam também por meio de costumes e regras não necessariamente escritas que concernem aos empregadores e assalariados de um ramo localizado em uma região os caminhos de colocar os compromissos locais em certa estabilidade.

Deste modo, o mercado de trabalho local tem uma dupla função na articulação da produção com o território: de promover recursos específicos, como o trabalho qualificado, e de servir como âmbito a construção de normas e regras de estabilização das relações de emprego locais por meio do coletivo de atores. No primeiro plano o trabalho aparece como um fator de concorrência entre lugares para localização das empresas com base em uma lógica espacial de custos e preços. Segundo a tipologia de Benko e Pecqueur (2001), a mão de obra quando não qualificada e não utilizada aparece como recurso e ativo genéricos, sendo o desempregado pouco qualificado um ativo, pois ele acaba pressionando o padrão salarial do mercado de trabalho local.

Já. o trabalho qualificado, aparece como recurso e ativo específico pois, como elemento de competitividade, sua formação técnica é um custo compartilhado pelo território e seus vários elementos. A segunda função caracteriza o mercado de trabalho local na articulação e confronto entre os atores locais no tocante as relações salariais. A relação salarial se define como instituição, pelo contrato de emprego e pela garantia legítima de salários diretos e indiretos, por meio de regras e convenções que regem a relação de emprego, o quadro sócio-institucional que produz tais regras, e os atores coletivos com seu modo de constituição, organização e interesses.

\section{ARRANJOS PRODUTIVOS E MERCADO DE TRA- BALHO LOCAL: CONSTRUINDO INTERDEPEN- DÊNCIAS}

Ao analisarem as múltiplas formas de reestruturação do processo produtivo e seu impacto na configuração territorial de sistemas industriais, Lipietz e Leborgne (1988) partem da premissa que as relações trabalhistas e profissionais se expressam diferentemente segundo os ramos e regiões onde se localizam. Essa múltipla influência setor-território se torna ainda mais nítida no espaço urbano, segmentado em espaço produtivo, espaço social e espaço de circulação, as três dimensões articuladas em um sistema único pelo "mercado de trabalho local", que estabelece a ligação entre indivíduos, empregos e salários (SCOTT, 1994, p. 35).

Considera-se que a atividade industrial ganha coerência espacial por meio de cadeias e circuitos produtivos ${ }^{5}$ que interligam partes de segmentos e ramos produtivos concatenados a um produto específico em concentrações localizadas. A análise dos mercados de trabalho localizados deve estar orientada, pois, para as

4 Segundo Baltar e Proni (1996), a enorme magnitude do desemprego é então, um dos fatores mais marcantes do desempenho recente do mercado de trabalho na Grande São Paulo, fenômeno que não foi revertido pela recuperação do ritmo de produção. Do aumento da população residente na metrópole entre 1989 e 1993, que foi de 860 mil pessoas, 64\% correspondem ao aumento do desemprego e só 36\% constituíram um elevado número de pessoas ocupadas. A taxa de desemprego, que havia aumentado de 8,7\% em 1989 para 15,3\% em 1992, continuava em 14,3\% em 1994 e ainda hoje (1996) situa-se num nível superior a 12\%.

5 Para Santos e Silveira (2001) um Circuito espacial de produção compreende o movimento de troca de fluxos de bens e serviços entre lugares especializados pela segmentação territorial das etapas do trabalho, em áreas não necessariamente contíguas. 
FUINI, L. L. Estudo do mercado de trabalho em arranjo produtivo local (APL) ...

partes territorializadas de cadeias, que a depender do nível de governança interna, podem constituir Arranjos produtivos Locais.

A noção de Arranjo produtivo local (APL) adquiriu proeminência no debate científico e nas estratégias de políticas públicas no Brasil e no mundo como instrumento de articulação dos atores locais a fim de elevarem a produtividade de um conjunto de empresas no uso dos recursos do território (BENKO; PECQUEUR, 2001, STORPER, 1993), promovendo competitividade e desenvolvimento territorial por meio de cooperação, complementariedade, inovação e trabalho qualificado. De forma resumida, um Arranjo Produtivo Local se refere a:

Aglomerações de empresas localizadas em um mesmo território, que apresentam especialização produtiva e mantêm algum vínculo de articulação, interação, cooperação e aprendizagem entre si e com outros atores locais tais como governo, associações empresariais, instituições de crédito, ensino e pesquisa (SEBRAE, 2003, p. 15).

Essas aglomerações de indústrias especializadas - também chamadas de clusters e distritos industriais - são o meio geográfico pelo qual os produtores em uma divisão social do trabalho (estabelecimentos especializados em diferentes atividades complementares) realizam as economias externas de escala, ou seja, o crescimento desses sistemas industriais urbanos é geralmente acompanhado por um suporte institucional de atividades e serviços que contribuem para a consolidação do desenvolvimento econômico local, suporte esse que pode assumir a forma de associações comerciais, estabelecimentos de ensino que ministram disciplinas úteis a localidade, joint-ventures e alianças estratégicas entre empresas, agências para-governamentais, etc. (SCOTT, 1994, p. 69 e STORPER; SCOTT, 1988, p. 36).

Essa complexidade relacional e sócio-institucional torna-se coerente por meio de formas de organização e distribuição de poderes na cadeia produtiva, chamada de "governança". Essa governança pode assumir formas mais hierarquizadas, no caso de uma grande empresa controlando um conjunto de subcontratados e fornecedores, e formas mais horizontais, no caso de um conjunto de pequenas e médias empresas compartilhando de objetos comuns (associações, poder público, mão de obra). (STORPER; HARRISON, 1994, p. 176-177).

Assim, um elemento chave e primordial que está na base do surgimento, reprodução territorial e dissolução de Arranjos produtivos locais, e até agora bastante ocultado na análise de aglomerados, são os "mercados de trabalho locais". Eles se constituem à medida que os complexos localizados de industrias se desenvolvem e crescem, atraindo para sua órbita espacial uma força de trabalho correspondente que incorpora as habilidades, qualificações e atributos requeridos pelos empregadores locais, características estas nem sempre negociáveis no mercado. Trata-se antes de tudo de economias de aglomeração derivadas da concentração de muitos trabalhadores em dado lugar, e que depois de formadas, ajudam a sustentar o padrão de crescimento localizado, influenciando decisivamente na expansão e retração de empregos no seio do mercado de trabalho local e na maior ou menor socialização e organização coletiva da força de trabalho (SCOTT; STORPER, 1988, p. 36-37).

Este estudo traz como idéia básica central, absorvida de outros autores (STORPER; WALKER, 1989), a possibilidade dos mercados de trabalho serem analisados geograficamente, já que a demanda e oferta de trabalho são diferenciadas por indústrias e lugares por meio de mecanismos de divisão espacial do trabalho, que na atualidade fazem emergir como componentes altamente competitivos os Arranjos produtivos locais.

Para tanto, um possível procedimento de pesquisa que possa tornar mais objetiva possível a análise da complexidade dos mercados de trabalho locais, é partir de algumas variáveis básicas imanentes as relações de emprego, obtidas na RAIS, e que podem dar um quadro consistente do mercado de trabalho local. São elas:

1) Características sociais gerais do mercado de trabalho local (emprego formal/informal/ desemprego);

2) Especialização da mão-de-obra local por porte e atividade do estabelecimento;

3) Instrução/qualificação da mão-de-obra;

4) Remuneração média da mão-de-obra (em salários mínimos);

5) Estrutura profissional (principais ocupações) $\mathrm{e}$

6) Flutuação do emprego (movimento de admissão e demissão).

Ao final, se obterá um retrato geral quantitativo do mercado de trabalho local coligado a territorialidade inerente ao APL de Santa Gertrudes. 
FUINI, L. L. Estudo do mercado de trabalho em arranjo produtivo local (APL) ...

\section{ESTUDO DE CASO: O MERCADO DE TRABALHO DA INDÚSTRIA DE REVESTIMENTOS CERÂMICOS DE SANTA GERTRUDES/SP}

A maior parte da produção brasileira de revestimentos cerâmicos está concentrada geograficamente na região sudeste e sul, sobretudo em torno das regiões produtoras de Santa Gertrudes (38\% do volume de produção nacional em 2003) e Criciúma, Santa Catarina (15,9\% do total, 2003), acompanhando a tendência mundial de concentração espacial da produção cerâmica em torno de determinadas regiões, como se verifica em Sassuolo, Itália, e Castellon, Espanha (MACHADO, 2003, p. 34).

A cerâmica de revestimento é material de construção civil usado para cobrir e dar acabamento a superfícies lisas (pisos, azulejos, ladrilhos e pastilhas), inserindo-se no âmbito da indústria de transformação de minerais não metálicos, dentro do complexo industrial de materiais de construção. A cadeia produtiva de revestimentos cerâmicos tem como elos principais as atividades de mineração, produção de massa, fabricação de cerâmica e construção civil, e como elos secundários o fornecimento de insumos sintéticos (esmaltados, pigmentos, corantes) e equipamentos, perfazendo 6 fases na linha de produção, percorrendo a mineração, mistura e moagem, conformação, esmaltação, queima e embalagem.

O contexto geográfico da indústria cerâmica de Santa Gertrudes é formado pelos municípios de Santa Gertrudes, Cordeirópolis, Rio Claro, Limeira, Araras, Piracicaba e Ipeúna (Figura. 1), concentrando em 2003 (RAIS, 2003) cerca de sessenta e oito estabelecimentos fabricantes de produtos cerâmicos para uso estrutural na construção civil (CNAE, Cadastro Nacional de Atividades Econômicas, 1995), setor que inclui a produção de pisos e azulejos, sem contar um número significativo de estabelecimentos fornecedores de insumos e matérias primas para as empresas do setor, configurando desse modo um sistema produtivo altamente concentrado que mobiliza cerca de 4.600 empregos formais diretos na produção principal e mais um sem número de empregos nos segmentos correlatos do Arranjo. Nos municípios de Santa Gertrudes, Cordeirópolis e Rio Claro é onde se localizam a maioria das empresas e dos empregos na produção cerâmica regional, sobretudo, no eixo rodoviário da Washington Luís. Santa Gertrudes respondia em 2001 por 38\% do volume da produção nacional, produzindo cerca de 180 milhões de metros quadrados de revestimentos.

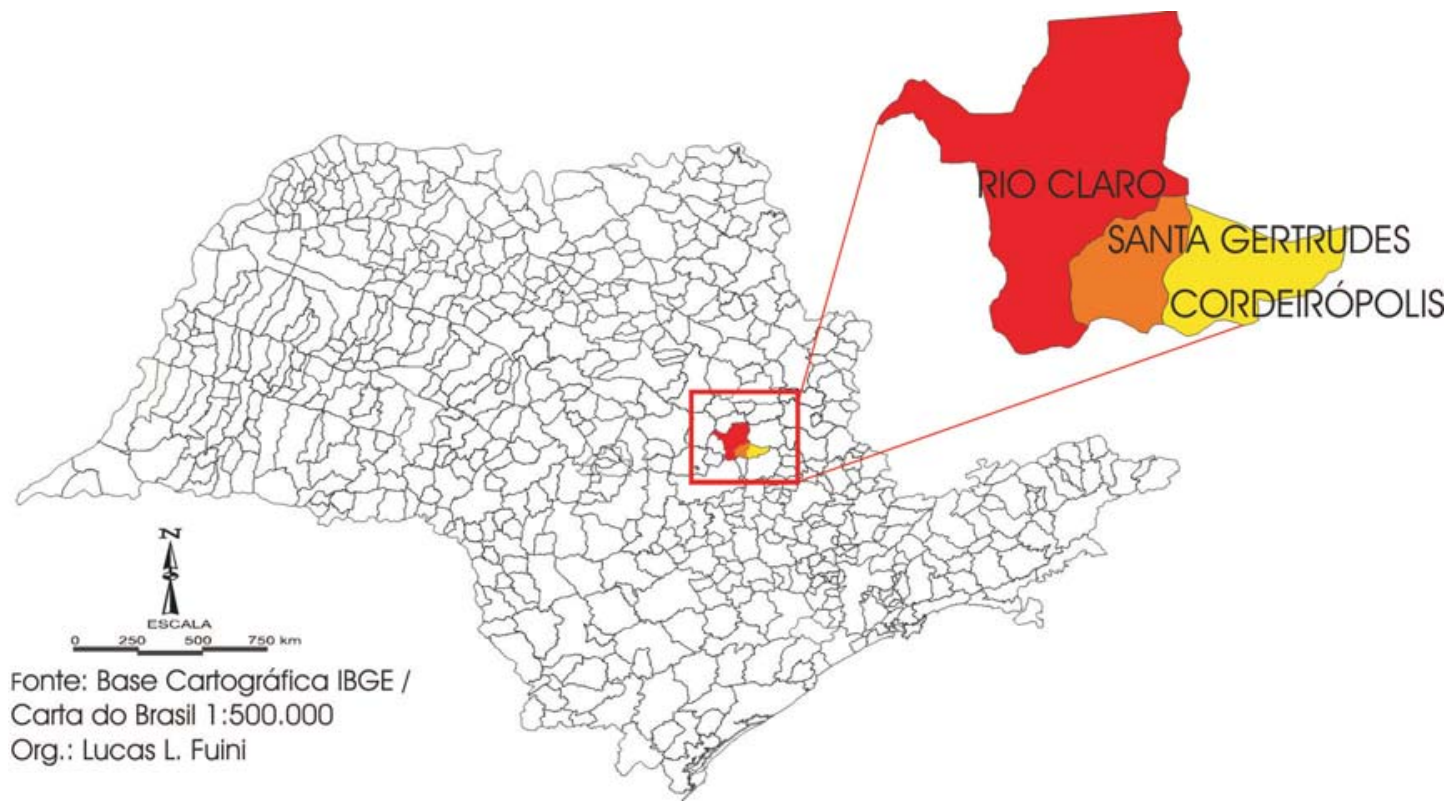

FIGURA 1 - MAPA DE LOCALIZAÇÃO DOS MUNICÍPIOS DO APL DE SANTA GERTRUDES 
FUINI, L. L. Estudo do mercado de trabalho em arranjo produtivo local (APL) ...

Uma das vantagens competitivas do APL de Santa Gertrudes é a boa qualidade e acabamento de seu produto, aliado ao seu baixo preço $(R \$ 5 \mathrm{~m} 2$ contra $R \$$ 8 reais de Criciúma). Além desses, outros elementos condicionantes da alta competitividade territorial de Santa Gertrudes é a oferta de matéria-prima de boa qualidade no local (argila Corumbataí) e a presença de mão de obra capacitada a operar na produção cerâmica (famílias tradicionais no ramo).

A análise do mercado de trabalho local de Santa Gertrudes se submeterá aos três municípios mais representativos já citados, utilizando dados da RAIS (Relatório Anual de Indicadores Sociais, Ministério do Trabalho e Emprego) para períodos selecionados (19972000-2003) e do IBGE (2000).

Quanto às condições de emprego mais gerais constata-se, no âmbito dos ocupados sem carteira, valores porcentuais levemente menores que os da metrópole paulistana, constatando a presença em mu- nicípios pequenos (Santa Gertrudes) de uma razoável quantidade de mão-de-obra na informalidade, apesar de contingente inferior aos dos grandes centros. Tais dados confrontados com as taxas de desemprego confirmam valores levemente menores que os da metrópole, indicando na visão de Storper e Scott (1988, p. 36) que os grandes mercados de trabalho locais tendem a apresentar taxas de desemprego maiores que os pequenos, pois tem uma dinâmica de rotatividade e recolocação entre candidatos a um emprego e vagas oferecidas maior que os pequenos mercados, onde as firmas tendem a resguardar seus empregados, dificultando a abertura de novos postos. Esse quadro serve então como alerta para o fortalecimento de políticas de emprego locais e regionais, a partir do que Pochmann (2000, p. 102) coloca:

Nos anos 90, dos 13,5 milhões que ingressaram no mercado de trabalho, apenas 8,5 milhões obtiveram acesso a algum trabalho, gerando um excedente de mão-de-obra de 5,1 milhões, ou seja, 37,5\% das pessoas que ingressaram no mercado.

TABELA 1 - CARACTERIZAÇÃO GERAL DO MERCADO DE TRABALHO LOCAL DO ENTORNO DE SANTA GERTRUDES

\begin{tabular}{l|l|c|l}
\hline & $\begin{array}{l}\text { TOTAL DE } \\
\text { OCUPADOS }\end{array}$ & SEM CARTEIRA & $\begin{array}{l}\text { NÚMERO DE } \\
\text { DESEMPREGADOS }\end{array}$ \\
\hline 1 - Santa Gertrudes & 6.348 & 977 & 946 \\
2 - Cordeirópolis & 7.434 & 990 & 1435 \\
3 - Rio Claro & 72.369 & 12253 & 11318 \\
4 - R. M. de São Paulo & 7204014 & 1533394 & 1.756 .205
\end{tabular}

FONTE: Censo: IBGE, 2000. Organizador: Lucas L. Fuini.

Outro elemento importante na análise dos mercados de trabalho locais é explorar os setores de atividade que configuram as relações de emprego locais, considerando a existência de uma especialização produtiva regional subsidiária de uma divisão espacial do trabalho imanente ao território brasileiro. Na região do APL de Santa Gertrudes encontram-se níveis bastante altos de especialização da mão de obra, ratificando a hipótese de que a atividade industrial de fabricação de revestimentos cerâmicos, organizada na forma de um APL, é o eixo estruturador do mercado de trabalho local. No caso dos municípios de Santa Gertrudes e Cordeirópolis, 48,3\% e $46,2 \%$ dos empregos formais, respectivamente, estão relacionados a atividade cerâmica. No índice Quociente de localização, Santa Gertrudes e Cordeirópolis apresentam valores altíssimos de concentração do emprego, superando em mais de vinte e sete vezes a média brasileira de concentração de empregos neste setor. Já em Rio Claro, apesar do número de empregos nessa atividade serem bastante representativos, a especialização encontra-se menos pronunciada em decorrência da base econômica e industrial de Rio Claro ser mais diversificada, sofrendo impacto também pronunciado de outros segmentos, como o de plásticos, químico, mecânico, etc. 
FUINI, L. L. Estudo do mercado de trabalho em arranjo produtivo local (APL) ...

TABELA 2 - ESPECIALIZAÇÃO DO EMPREGO NAATIVIDADE CERÂMICA NOS MUNICÍPIOS DO APL DE SANTA GERTRUDES

\begin{tabular}{l|l|l|l}
\hline & $\begin{array}{l}\text { INDÚSTRIA DE } \\
\text { TRANSFORMAÇÃO }\end{array}$ & $\begin{array}{l}\text { FABRICAÇÃO DE PRODUTOS } \\
\text { CERÂMICOS NÃO REFRATÁRIOS }\end{array}$ & QL Empregos \\
\hline 1 - Santa Gertrudes & 2.516 & 1.216 & 28,4 \\
$\mathbf{2}$ - Cordeirópolis & 2.725 & 1.261 & 27,2 \\
3 - Rio Claro & 14.472 & 950 & 3,8
\end{tabular}

FONTE: Rais, 2003. Organizador: Lucas L. Fuini

$\left(\mathrm{QL}\right.$ emprego $=\mathrm{n} 1 / \mathrm{N} 1 / / \mathrm{n} 2 / \mathrm{N} 2$, onde $\mathrm{n} 1=\mathrm{n}^{\circ}$ empregos na at ind. Transf. No município, $\mathrm{n} 2=\mathrm{n}^{\circ}$ empregos na atividade Brasil)

ividade específic. no municí pio, N1= no. Empregos na específic. no Brasil, N2= no. Empregos na ind. Transf. no

Outro elemento essencial na análise da relação entre estrutura produtiva e mercados de trabalho locais é quanto ao porte predominante dos estabelecimentos industriais do APL, fator que recai sobre a escala de produção obtida, a configuração técnica do trabalho, e às próprias relações profissionais. A maior parte dos empregos na produção de revestimentos cerâmicos de Santa Gertrudes está relacionada aos estabelecimentos de porte médio (91,6\% dos estabelecimentos de Santa Gertrudes são de médio porte), proporção adequada ao tipo de configuração técnica e parâmetro de competitividade da produção de revestimentos cerâmicos nacional e internacional, que passa a exigir dos estabelecimentos do ramo a obtenção de uma dada escala de produção e melhoria da eficiência e qualidade em consonância à infra-estrutura técnico-organizacional instalada e novas competência tecnológicas demandadas.
A dinâmica do mercado de trabalho local, considerando a evolução e mobilidade dos empregos nas atividades predominantes no contexto regional, se coloca também como mais um componente essencial ao estudo das relações de emprego locais visto que as alterações no emprego e desemprego da mão-de-obra são bastante freqüentes nas cidades. Na questão da expansão dos empregos na fabricação de revestimentos cerâmicos, considerando um período de seis anos, verifica-se um crescimento significativo e contínuo da base de empregos local na atividade de fabricação de revestimentos cerâmicos (Tabela 3).

Em Cordeirópolis, os empregos na atividade cerâmica cresceram, entre 1997 e 2003, cerca de 70\%, com um grande pico entre 2000 e 2003. Em Rio Claro houve um crescimento também na casa dos $70 \%$, com pico semelhante no último triênio.

TABELA 3 - DISTRIBUIÇÃO DOS EMPREGADOS NA ATIVIDADE CERÂMICA DE ACORDO COM O PORTE DO ESTABELECIMENTO

\begin{tabular}{l|c|c|c}
\hline & MICRO (0-9) & PEQUENOS (10-99) & MÉDIOS (100-499) \\
\hline 1 - Santa Gertrudes & 10 & 91 & $1.115(91,6 \%)$ \\
2 - Cordeirópolis & 0 & 326 & $935(74,1 \%)$ \\
3 - Rio Claro & 54 & 143 & $753(79,2 \%)$
\end{tabular}

FONTE: Rais, 2003. Organizador: Lucas L. Fuini.

É justamente no último triênio analisado que se verifica uma fase de expansão de empregos relacionada ao aumento do volume de produção na região, com investimentos em tecnologia e melhor organização institucional interna (estruturação da Associação paulista de produtores de cerâmica/ ASPACER), criando economias externas favoráveis à abertura de novos estabelecimentos e ampliação daqueles já existentes.

Quanto à mobilidade da mão-de-obra no mercado de trabalho local (tabela 4), verifica-se compor- tamentos parecidos nos períodos de 2004 e 2005. Nos dois períodos e para os três municípios, observa-se um saldo de movimentação positivo, ou seja, houve mais admitidos do que demitidos, confirmando a tendência de crescimento da base de empregos local nos últimos anos. Santa Gertrudes apresenta um saldo de movimentação mais pronunciado, natural, pois nesse município está concentrada a maior parte dos estabelecimentos do APL, enquanto Rio Claro apresenta valores mais modestos. 
FUINI, L. L. Estudo do mercado de trabalho em arranjo produtivo local (APL) ...

TABELA 4 - EVOLUÇÃO DOS EMPREGOS NA ATIVIDADE CERÂMICA DO APL DE SANTA GERTRUDES

\begin{tabular}{l|c|c|c}
\hline & $\mathbf{1 9 9 7}$ & $\mathbf{2 0 0 0}$ & $\mathbf{2 0 0 3}$ \\
\hline 1 - Santa Gertrudes & 0 & 855 & 1216 \\
2 - Cordeirópolis & 376 & 595 & 1.261 \\
3 - Rio Claro & 271 & 432 & 950
\end{tabular}

FONTE: Rais 1997, 2000, 2003. Organizador: Lucas L. Fuini.

Santa Gertrudes apresenta um comportamento anômalo na evolução dos empregos na fabricação de revestimentos cerâmicos, pois parte de uma base zero em 1997 para chegar a mais de 1.200 empregos em 2003. A inclusão da fabricação de revestimentos cerâmicos em outra classe de atividade CNAE (2642-9 Fabricação de produtos cerâmicos não refratários para usos diversos), segundo às mudanças na metodologia RAIS, se refletiu posteriormente em uma transferência de empregos de outras atividades do ramo cerâmico (fabricação de vasos, recipientes e objetos de cerâmica artesanal e semi-industrial), que concentravam cerca de 1.792 empregos formais em 1997, para a produção fabril de pisos e azulejos em expansão.

A qualificação e instrução da mão-de-obra (tabela 5) perfazem um outro elemento indispensável à análise do mercado trabalho local, considerando a aquisição de educação formal pelos trabalhadores, como elemento que facilita a obtenção de conhecimentos especializados, hábitos e práticas inovadoras adequadas ao sistema industrial local. A instrução média da mão-deobra apresenta nos três anos analisados, a partir dos módulos completos e incompletos cursados pelos empregados, predomínio do nível fundamental de instrução (até $8 a$. série). Já se verifica, no entanto, um sensível aumento dos anos de estudo da mão-de-obra visto que a quantidade absoluta e relativa daqueles que estavam cursando o ensino médio e superior tem crescido ano a ano e, aqueles que estão no nível fundamental, tem decaído.

O panorama acima descrito indica um aumento das exigências por maior qualificação da mão-de-obra em decorrência de mercados cada vez mais exigentes nos quais se projeta o APL de Santa Gertrudes, exigindo medidas no sentido de oferecer cursos de nível básico e superior, em intercâmbio com instituições públicas e privadas, voltados à capacitação de seus funcionários, que ainda se encontram, em sua maioria, em um patamar intermediário de instrução. A ASPACER (Associação Paulista de Produtores de Cerâmica com sede em Santa Gertrudes) tem tomado medidas recentes visando incrementar os saberes técnicos dos trabalhadores da região.

TABELA 5 - INSTRUÇÃO MÉDIA DOS EMPREGADOS NA PRODUÇÃO DE REVESTIMENTOS CERÂMICOS DE SANTA GERTRUDES

\begin{tabular}{|c|c|c|c|c|c|c|c|c|c|c|c|c|c|}
\hline & \multicolumn{4}{|l|}{1997} & \multicolumn{4}{|l|}{2000} & \multicolumn{5}{|l|}{2003} \\
\hline & $\overline{\mathbf{A}}$ & $F$ & M & $\mathrm{S}$ & $\bar{A}$ & $F$ & $M$ & $\bar{S}$ & $\mathbf{A}$ & $F$ & $M$ & $S$ & \\
\hline 1 -Cordeirópolis & 8 & $\begin{array}{r}281 \\
(74,7 \%)\end{array}$ & 73 & 14 & 13 & $\begin{array}{r}392 \\
(65,8)\end{array}$ & $\begin{array}{r}16 \\
8\end{array}$ & 22 & 18 & $\begin{array}{r}825 \\
(65,4 \%)\end{array}$ & 352 & & 66 \\
\hline 2 - Rio Claro & 16 & $\begin{array}{r}233 \\
(85,9 \%)\end{array}$ & 19 & 3 & 3 & $\begin{array}{c}347 \\
(80,3)\end{array}$ & 70 & 12 & 7 & $\begin{array}{r}589 \\
(62 \%)\end{array}$ & 309 & & 45 \\
\hline 3 - Santa Gertrudes & 0 & 0 & 0 & 0 & 18 & $\begin{array}{r}646 \\
(75,5)\end{array}$ & $\begin{array}{r}15 \\
9\end{array}$ & 32 & 7 & $\begin{array}{r}733 \\
(60,2 \%)\end{array}$ & 401 & & 75 \\
\hline
\end{tabular}

FONTE: Rais, 1997, 2000, 2003. Organizador: Lucas L. Fuini.

A: Analfabetos = 0 ano de estudo; F: fundamental ( 1 a 8 anos de estudo); M: médio (8 a 10 anos de estudo), S: ensino superior (+ 10 anos de estudo) 
A remuneração da mão-de-obra (Tabela 6) é um outro aspecto fundamental dos mercados de trabalho locais, visto que o salário é para a empresa um instrumento de seleção, de formação e de incitação da mão de obra, refletindo um movimento de aprofundamento da divisão técnica do trabalho e estratificação do estatuto dos assalariados nas empresas de acordo as especialidades, postos de trabalhos e profissões exercidas (PIRES, 2002, p. 175-176). Quanto à remuneração média mensal, quando avaliada em valores (Reais $-R \$$ ), verifica-se um aumento dos rendimentos em todos os municípios, com acréscimos em valores na casa dos 150 a 200,00 reais no período de seis anos.
Mas, se avaliarmos pelos Salários mínimos (s.m.), observa-se uma relação de declínio da ren$\mathrm{da}$, inversamente proporcional aos valores nominais. Tratando o salário mínimo como uma renda básica necessária à reprodução do indivíduo e que se ajusta conforme os custos de vida de cada período, observa-se que na verdade houve senão um declínio da renda do trabalhador, pelo menos um achatamento da mesma, ressaltando que o aumento dos rendimentos, em valores na moeda corrente, indica apenas uma trajetória que acompanha o aumento do valor do salário mínimo, portanto, tendo sempre os níveis de rendimento mais baixos como referência.

TABELA 6 - REMUNERAÇÃO MÉDIA MENSAL DOS EMPREGADOS NA PRODUÇÃO DE REVESTIMENTOS CERÂMICOS DE SANTA GERTRUDES EM VALORES ABSOLUTOS (R\$) E SALÁRIOS MÍNIMOS (s.m.)

\begin{tabular}{|c|c|c|c|c|c|c|}
\hline & \multicolumn{2}{|c|}{$1997(\mathrm{R} \$ 135,00)$} & \multicolumn{2}{|c|}{$2000(R \$ 148,00)$} & \multicolumn{2}{|c|}{$2003(\mathrm{R} \$ 232,00)$} \\
\hline 1 - Santa Gertrudes & 0 & 0 & 705,38 & 4,78 s.m. & 975,17 & $\begin{array}{l}4,18 \\
\text { s.m. }\end{array}$ \\
\hline 2 - Cordeirópolis & 658,80 & 4,87 s.m. & 633,84 & 4,28 s.m. & 882,05 & 3,8 s.m. \\
\hline 3 - Rio Claro & 597,60 & 4,44 s.m. & 641,49 & 4,34 s.m. & 922,05 & $\begin{array}{l}3,96 \\
\text { s.m. }\end{array}$ \\
\hline 4 - Estado de S. Paulo & 608,54 & 4.5 s.m. & 690,62 & 4,68 s.m. & 926,18 & $\begin{array}{l}3,98 \\
\text { s.m. }\end{array}$ \\
\hline
\end{tabular}

A remuneração média na produção de revestimentos cerâmicos apresenta sensíveis variações conforme a função exercida na empresa e o grau de instrução do trabalhador. Por exemplo, os trabalhadores da cerâmica no município de Santa Gertrudes, no cargo de ceramistas engajados na linha de produção, têm uma renda mensal de 814 reais, já no cargo de supervisor de fabricação, tem renda de 1.673,00, enquanto no cargo de engenheiros eletricistas e eletrônicos, tem renda de $2.126,00$ reais. No caso do nível de instrução observase a mesma tendência. No município de Cordeirópolis, um trabalhador com 4a. Série completa apresenta renda de até 3,11 s.m., para aquele com 8a. Série completa, a renda é de 3,8 s.m., com nível 20. Grau, é de 4,06, e para aqueles com nível superior completo, é de 7,4 s.m.

Por fim, outro dos elementos singulares das relações de emprego locais é a estrutura de ocupações do mercado de trabalho local, compreendendo nesse item as características técnicas da mão de obra e as expectativas dos empregadores quanto às qualificações da mão de obra. As ocupações que absorvem mais mão-de-obra são aquelas ligadas diretamente à linha de produção e manutenção do processo produtivo, as mesmas que aparecem nos patamares de renda mais baixos.

TABELA 7 - PRINCIPAIS OCUPAÇÕES DOS EMPREGADOS NA INDÚSTRIA DE TRANSFORMAÇÃO EM MUNICÍPIOS SELECIONADOS

\begin{tabular}{l|c|c|c|c}
\hline & $\begin{array}{c}\text { 1 - Ceramista } \\
\text { (fabricação/preparação) }\end{array}$ & $\begin{array}{c}\text { 2 - Mecânicos de Manut. } \\
\text { de Máquinas Industrais }\end{array}$ & $\begin{array}{c}\text { 3 - Escriturários em } \\
\text { geral, assistentes, etc. }\end{array}$ & TOTAL \\
\hline 1- Santa Gertrudes & 1101 & 174 & 129 & 2.516 \\
2 - Cordeirópolis & 566 & 144 & 116 & 2.726
\end{tabular}

FONTE: Rais, 2003. Organizador: Lucas L. Fuini. 
FUINI, L. L. Estudo do mercado de trabalho em arranjo produtivo local (APL) ...

\section{CONSIDERAÇÕES FINAIS}

Este trabalho teve como um dos seus objetivos principais contribuir para a melhor compreensão da influência exercida pelos mercados locais de trabalho sobre sistemas e arranjos produtivos localizados, tendo em vista a (re) configuração do papel do emprego e dos sistemas de produção na compreensão atual da organização dos territórios.

Nesse estudo, a partir de algumas variáveis chaves, foi possível delinear um panorama do comportamento da mão-de-obra inserida no contexto territorial do aglomerado cerâmico da região de Santa Gertrudes, enfatizando a dinâmica desse mercado de trabalho local em alguns de seus aspectos positivos, como a melhoria das condições de instrução dos empregados locais, e negativos, como a relativa estagnação da renda salarial média da mão-de-obra empregada na indústria.

O artigo expõe dados secundários da base RAIS e do Censo IBGE a fim de se obter um panorama da configuração do mercado de trabalho, na escala local/ regional, associado aos municípios paulistas que participam do arranjo de produção cerâmica de Santa Gertrudes. A partir da análise de alguns elementos típicos da dinâmica do mercado de trabalho, como; evolução na geração de empregos, especialização setorial do mercado de trabalho, remuneração, instrução da mão-de-obra; chegou-se a um quadro sócio-territorial do mercado de trabalho em um APL. Desse quadro, delinearam-se alguns apontamentos conclusivos: a extrema especialização setorial da atividade produtiva, oscilações quanto à geração de empregos e da remuneração acompanhando a oscilação do ritmo produtivo, aumento do patamar de instrução da mão-de-obra acompanhando o crescimento e adensamento tecnológico do arranjo; estrutura de ocupações concentrada em atividades voltadas à produção propriamente dita, etc.

Outros elementos podem ser adicionados em um estudo desse caráter, sobretudo no que tange as políticas locais de emprego e a participação local dos sindicatos e associações representativas em torno do conflito capital e trabalho. Tais problemáticas podem servir como tema para análises posteriores no sentido de caracterizarem com amplitude os processos dinâmicos de construção e reconstrução das relações de emprego locais que configuram os mercados de trabalho locais.

Em síntese, neste texto tratou-se de buscar na base de análise local e regional, dentro do enfoque territorial, uma ancora possível de articulação dos mo- vimentos de transformações do mundo do trabalho e dos sistemas produtivos, oferecendo mais uma contribuição aos estudos geográficos sobre o tema trabalho e mercado de trabalho.

\section{REFERÊNCIAS}

BALTAR, P. E. A.; PRONI, M. W. Sobre o Regime de trabalho no Brasil: Rotatividade da Mão de obra, emprego formal e estrutura salarial. In: OLIVEIRA, C. A. B. de (Org.). Crise e Trabalho no Brasil: Modernidade ou volta ao passado? Campinas: Scritta, 1996, p.109-150.

BENKO, G. Economia, Espaço e Globalização: Na aurora do século XXI. São Paulo: Hucitec, 1996.

BENKO, G. A Recomposição dos espaços. Revista Internacional de Desenvolvimento Local-Interações. Campo Grande/ MS, v. 1, n. 2, p. 7-12, 2001.

BENKO, G.; PECQUEUR, B. Os recursos de territórios e os territórios de recursos. Geosul. Florianópolis, v. 16, n. 32, p. 31-50, jul./dez. 2001.

GEORGE, P. Populações Ativas. São Paulo: Difel, 1979.

LASTRES, H. M. M. et al. Globalização e Inovação Localizada. In: CASSIOLATO, J. E.; LASTRES, H. M. (Org.). Globalização e Inovação Localizada: Experiências de sistemas locais no Mercosul. Brasília: IBICT/MCT, p. 39-71, 1998.

LIPIETZ, A.; LEBORGNE, D. O pós-fordismo e seu espaço. Espaços e Debates. São Paulo, n. 25, p. 19-29, 1988.

MACHADO, S. A. Dinâmica dos Arranjos Produtivos Locais: um estudo de caso em Santa Gertrudes: a nova capital da cerâmica brasileira. 125 f. Tese (Doutorado em Engenharia de Produção) - Escola Politécnica, Universidade de São Paulo, São Paulo, 2003.

MATTOSO, J. A desordem do trabalho. São Paulo: Scritta, 1995.

PIRES, E. L. S. Crise de regulação e possibilidades da relação salarial no capitalismo contemporâneo. In: SILVA, J. P., DOS SANTOS, M. S.; RODRIGUES, I. J. (Org.). Crítica Contemporânea: Cultura, Trabalho, Racismo e Política, São Paulo, Ed. Anna Blume, p. 169-194, 2002.

POCHMANN, M. O Emprego na Globalização: A nova ordem internacional e os caminhos que o Brasil escolheu. São Paulo: Boitempo, 2001.

SANTOS, M.; SILVEIRA, M. L. O Brasil: Território e Sociedade no início do séc. XXI. RJ: Record, 2001.

SEBRAE. A Mobilização Interna dos Territórios para o Desenvolvimento. Brasília: Abril de 2003. Versão preliminar p/ 
Discussão Interna. Disponível em: <www.sebrae.com.br>. Acesso em: 16/10/2004.

SCOTT, A. J. A Economia Metropolitana. In: BENKO, G.; LIPIETZ, A. (Org.). As Regiões Ganhadoras. Distritos e Redes: Os novos paradigmas da geografia econômica. Oeiras: Celta, p. 63-76, 1994.

SCOTT, A; STORPER, M. Indústria de Alta Tecnologia e Desenvolvimento Regional: uma crítica e reconstrução teórica. Espaço e Debates, São Paulo, v. 2, n. 25, p. 30-44, 1988.

STORPER, M. Territorialização numa Economia Global: potencialidades de desenvolvimento tecnológico, comercial e regional em economias subdesenvolvidas. In: LAVINAS, L., CARLEIAL, L. M.; NABUCO, M. R. (Org.). Integração, Região e Regionalismo. São Paulo: Bertrand Brasil, p. 13-26, 1993.

STORPER, M. e HARRISON, B. Flexibilidade, Hierarquia e Desenvolvimento Regional: As mudanças de estrutura dos sistemas produtivos industriais e seus novos modos de Governância nos anos 90. In: BENKO, G.; LIPIETZ, A. (Org.). As Regiões Ganhadoras. Distritos e Redes: Os novos paradigmas da geografia econômica. Oeiras: Celta, p. 171-187, 1994.

STORPER, M.; WALKER, R. The Capitalist Imperative: Territory, Technology, and Industrial Growth. Oxford: Basil Blackwell, 1989. 
